\title{
Introduction: Information from physics to social science
}

\author{
W. Hofkirchner ${ }^{\mathrm{a}}$ \\ Vienna University of Technology; Bertalanffy Center for the Study of Systems Science, \\ Vienna, \& International Society for Information Studies, Vienna, Austria
}

Received 25 November 2016 / Received in final form 25 November 2016 Published online 10 February 2017

Disciplines abound with research into information, information society and information technology. They have been using diverse information concepts generalised from findings according to different approaches. However, it has been likewise an intrinsic feature of science to attempt consilience and to strive for complementarity, compatibility, and consistency of knowledge, if not unification of theories at all. That process appears in the field of information too, raising questions with respect to the interrelation of disciplinary accounts (starting with [1]; and continuing, among others, in the journal [2], and the latest volumes in the book series in information studies [3] and [4]). Which role does physics play in that respect? And which roles do chemistry, life sciences as well as social and human sciences play as compared to physics? And which are the roles they should play if a more consilient account of information shall be achieved?

Physics is deemed to be the most fundamental real-world science. Although its outstanding role seems thus undisputed, it would be a fallacy to believe in the possibility of a blunt reduction (a) of practical information problems to problems that can be solved by a physical approach alone; (b) of any real-world information phenomenon to mere physical information phenomena; and (c) of theories of disciplines other than physics to, eventually, physical theories. It seems more fruitful to understand the role of physics - as, e.g., Ebeling and Feistel [5] did - as providing (a) the most basic toolkit for problem solving tools of any kind (since any practical activity necessitates some physical implementation); (b) a scope of possibilities some of which are realised in a contingent process, thereby providing necessary but not sufficient conditions for the emergence of nested systems and levels; and (c) theories that cover the most general real-world features and work as presuppositions of more sophisticated theories that are enriched with causative factors going beyond the physical level but indispensably being rooted in the physical level.

Such a perspective is supported by ideas of complexity research, the evolutionary systems approach and Ludwig von Bertalanffy's General System Theory [6]. According to that perspective, science and technology would enable civilisation to meet complex challenges, to provide knowledge about the working of complex systems, and to understand how phenomena that exhibit different levels of complexity can in theory and practice - be related to each other. Given a lower complex phenomenon and a higher complex phenomenon, both can be connected through integration and

\footnotetext{
a e-mail: wolfgang.hofkirchner@bcsss.org
} 


\begin{tabular}{|c|c|c|c|}
\hline & complexities & identity and differences \\
\hline \multirow[b]{2}{*}{$\begin{array}{l}\text { absolut- } \\
\text { ism }\end{array}$} & $\begin{array}{l}\text { reduction- } \\
\text { ism }\end{array}$ & \begin{tabular}{|l|} 
levelling down \\
higher complexity
\end{tabular} & $\begin{array}{l}\text { identity at the cost of differences } \\
\text { (monism: uniformity not diversity) }\end{array}$ \\
\hline & $\begin{array}{l}\text { projection- } \\
\text { ism }\end{array}$ & $\begin{array}{l}\text { levelling up lower } \\
\text { complexity }\end{array}$ & $\begin{array}{l}\text { identity for the benefit of one difference } \\
\text { (monism: uniformity not diversity) }\end{array}$ \\
\hline \multicolumn{2}{|c|}{$\begin{array}{l}\text { relativism: } \\
\text { disjunctionism }\end{array}$} & \begin{tabular}{|l|} 
disjoining \\
degrees of \\
complexity \\
\end{tabular} & $\begin{array}{l}\text { differences at the cost of identity } \\
\text { (dualism: plurality not unity) }\end{array}$ \\
\hline \multicolumn{2}{|c|}{$\begin{array}{l}\text { emergentist } \\
\text { systemism way of } \\
\text { thinking: } \\
\text { integrationism }\end{array}$} & \begin{tabular}{|l|} 
linking \\
complexity \\
degrees through \\
integration and \\
differentiation
\end{tabular} & $\begin{array}{l}\text { identity and differences united } \\
\text { (dialectics: unity through diversity) }\end{array}$ \\
\hline
\end{tabular}

Fig. 1. Ways of thinking.

differentiation, that is, both phenomena are identical and different at the same time: the phenomenon with a lower degree of complexity shares with the phenomenon with a higher degree of complexity at least one property, which makes them, to a certain extent, identical, while the higher complex phenomenon is in the exclusive possession of at least another property, which makes it, to a certain extent, distinct from the lower complex one. The last property is an emergent property. Thus the term "emergentist systemism" [7] for an integrationist approach to complex systems (see Fig. 1).

Reductionism would, essentially, level down higher complexity. Levelling up lower complexity can be called projectionism. Reduction or projection would establish absolute identity. The attempt to disjoin complexities, resulting in disjoint differences, is relativism. Reduction, projection, or disjunction would fail to grasp complexity [8].

Along these lines, a new inter- and trans-disciplinary information concept has been emerging, doing justice to a proper role of physics as well as other real-world sciences. The collected papers converge on that perspective. The authors stand in the forefront of the development of the sciences of information in their own right with physics as point of departure.

The range of the ten contributions gathered here cover domains from physics to social science and information and communication technologies. Werner Ebeling starts with an emphasis on entropy and discusses different concepts and their relation to information [9]. Rainer E. Zimmermann pairs entropy with structure and energy with mass [10], the first pair representing information and the second one matter, both present from the beginning on such that loops of energy and entropy processing constitute agents in the sense of Stuart Kauffman. Gordana Dodig-Crnkovic's info-computationalism looks upon the whole universe as populated by informational agents, nature processes information, which is called computation [11]. Gyorgy Darvas focuses on how information processes can enter the stage at the level of interaction of inanimate particles [12]. Rainer Feistel progresses to the level of living systems the evolutionary rise of which he sees connected with symbolic information [13]. Ron Cottam, Willy Ranson and Roger Vounckx as well as David Weinbaum and Viktoras Veitas deal with problems of cognition in living systems, the first group with respect to complex aspects of hierarchy and introducing Peircean semiotic considerations [14], the second group with respect to the emergence of intelligent behaviour [15]. The last three authors extend the emergence of intelligence to the social level by distributed information processes. Sayfan Borghini presents case studies to demonstrate the usefulness of the concept of stigmergy - the interaction of agents through traces in their environment - in the design of social systems [16]. 
Francis Heylighen introduces chemical reaction networks to model self-organised sociotechnical systems that, eventually, could transform our current information society into a global brain for our planet [17]. And Dirk Helbing suggests a decentralised digital nervous system - called Nervousnet - to make flawed top-down control in social systems obsolescent [18].

\section{References}

1. W. Hofkirchner (ed.), The Quest for a Unified Theory of Information, Proceedings of the Second International Conference on the Foundations of Information Science (Gordon and Breach, Amsterdam, 1999)

2. Information 1 (2010)-7 (2016)

3. W. Hofkirchner, M. Burgin. (eds.), The Future Information Society: Social and Technological Problems (World Scientific Publishing, Singapore, 2017)

4. M. Burgin, W. Hofkirchner (eds.), Information Studies and the Quest for Transdisciplinarity (World Scientific Publishing, Singapore, 2017)

5. W. Ebeling, R. Feistel, in Chaos und Kosmos (Spektrum, Heidelberg, 1994), p. 25

6. L.v. Bertalanffy, General System Theory, With a Foreword by Wolfgang Hofkirchner and David Rousseau (George Braziller, New York, Revised Edition, 18th paperback printing, 2015)

7. P.Y. Wan, Reframing the Social, Emergentist Systemism and Social Theory (Ashgate, Farnham, 2011)

8. W. Hofkirchner, Emergent Information, A Unified Theory of Information Framework (World Scientific Publishing, Singapore, 2013)

9. W. Ebeling, Physical basis of information and the relation to entropy, Eur. Phys. J. Special Topics 226, 161 (2017)

10. R.E. Zimmermann, Matter and information as attributes of substance, Eur. Phys. J. Special Topics 226, 177 (2017)

11. G. Dodig-Crnkovic, Nature as a network of morphological infocomputational processes for cognitive agents, Eur. Phys. J. Special Topics 226, 181 (2017)

12. G. Darvas, A few questions related to information and symmetries in Physics, Eur. Phys. J. Special Topics 226, 197 (2017)

13. R. Feistel, Self-organisation of symbolic information, Eur. Phys. J. Special Topics 226, 207 (2017)

14. R. Cottam, W. Ranson, R. Vounckx, Precognition and the metascalar nature of information, Eur. Phys. J. Special Topics 226, 229 (2017)

15. D. Weinbaum, V. Veitas, Synthetic cognitive development, Eur. Phys. J. Special Topics 226, 243 (2017)

16. S.G. Borghini, Stigmergy in the design of social environments, Eur. Phys. J. Special Topics 226, 269 (2017)

17. F. Heylighen, The offer network protocol: Mathematical foundations and a roadmap for the development of a global brain, Eur. Phys. J. Special Topics 226, 283 (2017)

18. D. Helbing, From remote-controlled to self-controlled citizens, Eur. Phys. J. Special Topics 226, 313 (2017) 